\title{
西双版纳热带雨林地区冬季辐射雾理化特征的 观测研究
}

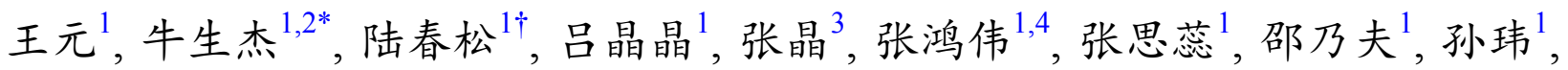
靳雨晨 ${ }^{1}$, 宋清海 ${ }^{3}$

1. 南京信息工程大学气象灾害预报预警与评估协同创新中心, 中国气象局气溶胶与云降水重点开放实验室, 南京 210044;

2. 南京工业大学安全科学与工程学院, 南京 210009 ;

3. 中国科学院热带森林生态学重点实验室, 预仑 666303 ;

4. 河南省气象探测数据中心, 郑州 450003

* 通讯作者, E-mail: niusj@nuist.edu.cn

†通讯作者, E-mail: luchunsong110@gmail.com

收稿日期: 2020-11-22; 收修改稿日期: 2021-03-19; 接受日期: 2021-04-01; 网络版发表日期: 2021-09-29

国家自然科学基金项目(批准号: 41775134、41822504、41675136和41671209)和江苏省研究生科研创新计划项目(编号: KYCX20_0920)资助

摘要本文分析了2019年冬季西双版纳热带雨林地区的辐射雾探测试验资料, 夜间长波辐射冷却结合森林内高 湿、微风的环境和较低的气溶胶浓度促进雾的生成和维持, 正午前因湍流增强导致雾层抬升或消散. 雾的微物理 特征为: 雾滴数浓度低, 雾滴粒径大, 液态含水量较高, 滴谱相对谱宽较窄, 过饱和度高; 其化学特征为: 雾水呈弱 碱性, 电导率低, 雾水中占比最高的阴、阳离子分别为 $\mathrm{Cl}^{-}$和 $\mathrm{Ca}^{2+}$, 且化学组分在小滴富集. 依据 $\kappa$-Köhler理论间接 计算雾中过饱和度, 结果发现在较低过饱和度时雾滴谱存在凝结拓宽现象; 过饱和度制约雾中关键微物理过程, 与雾滴数浓度呈正相关, 与雾滴体积平均直径呈负相关.

关键词辐射雾, 生消机理, 理化特征, 水汽过饱和度, 热带雨林地区

\section{1 引言}

雾是近地层大气中悬浮的大量微米尺度液滴或冰 晶的集合体，本质上为气溶胶在过饱和条件下活化的 产物. 雾发生于近地层, 对人类活动有显著的影响. 由 于雾滴对可见光的衰减作用，雾中较低的能见度对海 陆空交通产生严重危害，其损失与龙卷风甚至是台风
造成的损失相当(Gultepe等, 2007). 雾形成时的逆温层 结构促进污染物累积, 且液滴表面水膜加速二次污染 形成，加剧大气污染，损害人体健康(Mazzoleni等, 2010; 郭丽君等, 2015; 牛生杰等, 2016). 雾作为一种 灾害性天气而备受关注. 自20世纪70年代以来, 国内外 开展广泛的外场科学实验, 探究各类雾的生消机理和 理化特征(雾滴的粒径分布特征和化学组分特征). 例

\footnotetext{
中文引用格式: 王元, 牛生杰, 陆春松, 吕晶晶, 张晶, 张鸿伟, 张思荵, 邵乃夫, 孙玮, 靳雨晨, 宋清海. 2021. 西双版纳热带雨林地区冬季辐射雾理化特征的观测 研究. 中国科学: 地球科学, 51(12): 2098-2111, doi: 10.1360/SSTe-2020-0332

英文引用格式: Wang Y, Niu S, Lu C, Lv J, Zhang J, Zhang H, Zhang S, Shao N, Sun W, Jin Y, Song Q. 2021. Observational study of the physical and chemical characteristics of the winter radiation fog in the tropical rainforest in Xishuangbanna, China. Science China Earth Sciences, 64(11): 1982-1995, https://doi.org/10.1007/s11430-020-9766-4
} 
如美国CALSPAN海雾试验(Pilié等，1979)、加拿大 FRAM试验(Gultepe等，2009)、意大利波河河谷试验 (Fuzzi等，1992)、法国PARISFOG试验(Haeffelin等, 2010); 在国内, 开展衡山、泰山和庐山云雾试验(顾震 潮, 1980; 王体健等, 2019), 重庆雾害研究(李子华和彭 中贵, 1994), 南岭山地雾试验(吴兄等, 2007), 南京北郊 冬季雾观测试验(养梅娟等, 2008; 陆春松等, 2010; Niu 等, 2012), 以及湛江海雾研究(吕晶晶等, 2014)等.

雾还具备重要的生态学意义(张晶等, 2018), 雾水 沉降是多雾森林生态系统重要的水文和化学输入项 (刘文杰等, 2004; Degefie等, 2015). 西双版纳热带雨林 地区是东南亚热带雨林分布的最北缘, 也是我国大陆 热带雨林集中分布的重要区域. 在每年的雾凉季(11月 至翌年2月), 雾水的输入有效地缓解了干季森林内浅 层土壤水分的缺失, 为森林植被提供有利的生长环境 (Liu等, 2010). 1997年11月, 南京气象学院在西双版纳 城郊开展为期 1 周的雾外场试验，通过在 4 场辐射雾过 程中获得的观测数据, 研究该地区雾的生消机理(兴梅 娟等, 2001)、理化特征(黄玉生等, 2000; 朱樹等, 2000) 及对生态环境变化的响应(黄玉仁等, 2000), 并开展局 地雾的数值模拟试验(黄建平等, 2000). 由于此次试验 的观测站点位于城郊, 一定程度上受到人为活动影响. 且随着森林覆盖率的减少, 西双版纳雾日数正在以平 均每十年10 27天的速度锐减(宫世贤和凌升海，1996; 马友金等, 1999), 这意味着雾的生消机理和理化特征 极可能也在发生着变化.

为进一步深入探究热带雨林地区冬季辐射雾特 征, 2019年冬季, 南京信息工程大学在西双版纳热带雨 林地区再次开展辐射雾综合探测试验. 同时, 重点关注 雾中水汽过饱和度的分布情况，及其对雾微物理量的 影响. 过饱和度对气溶胶的活化过程和云雾滴的凝结 增长过程产生影响, 是制约云雾微物理过程的关键因 素. 但由于其直接测量的精度难以满足研究需要, 如 LI-COR的水汽分析仪测量精度的绝对误差为 $1 \%($ Korolev和Isaac, 2006), 在以往的云雾试验研究中过饱和 度很少被关注. 本文根据 $\kappa$-Köhler理论(Petters和Kreidenweis, 2007), 使用气溶胶和雾的观测结果间接计算 雾中过饱和度, 从过饱和度的角度, 更深入剖析雾在不 同阶段的微物理机理.

在西双版纳热带雨林地区开展雾理化特征的综合 观测试验, 是加深对该地区雾的认识和理解的有效手
段. 基于此次试验结果，本文一方面将探究该地区雾 的生消机制和理化特征, 并从过饱和度的角度研究雾 中活化、凝结和碰并过程, 从而推动该地区雾微物理 参数化的建立, 提高局地雾的预报效果; 另一方面, 对 比1997年西双版纳城郊地区冬季辐射雾观测结果, 探 究雾理化特征的差异和影响因子, 并为该地区雾的生 态价值评估提供科学依据.

\section{2 数据和方法}

\section{1 观测简介}

为深入探究热带雨林地区辐射雾的理化性质, 在 2019年冬季(2019年11月22日至2020年2月28日), 南京 信息工程大学大气物理学院雾研究团队与中国科学院 热带森林生态学重点实验室的研究人员合作, 在西双 版纳热带雨林地区开展了为期 3 个月的雾理化特征的 外场综合探测试验(XSBN-FOG-2019). 观测点及其周 边环境如图1所示.

本次试验中, 我们使用三级分档雾水采集器 CASCC-3stage(Caltech Active Strand Cloudwater Collector with 3 stages)收集不同粒径段的雾水样品. 雾水 化学采样点位于西双版纳预仑镇中国科学院西双版纳 热带植物园内, CASCC-3stage架设于旧生态站楼顶(距 地高度约 $10 \mathrm{~m}$, 如图1a所示); 周边山丘林立, 草木笼罩, 且毗邻南班江, 水汽充沛, 利于收集雾水. CASCC3stage(Collett Jr.等, 1995), 可同时采集直径在4 16 $\mu \mathrm{m}$

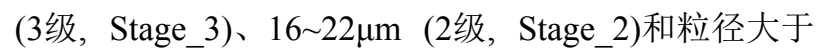
$22 \mu \mathrm{m}$ (1级, Stage_1)的雾滴, 切割率为 $50 \%$. 当CASCC3 stage采集到雾水时, 使用Metrohm827台式pH计和 DDS-11A 电导率仪现场测定雾水样品的 $\mathrm{pH}$ 和电导率 $(E C)$, 后将雾水装入收集瓶中, 并用锡纸完全包裹后置 于冰箱冷藏, 待后续实验分析. 在实验室内, 使用 $\mathrm{Me}-$ trohm850 Professional IC型离子色谱仪测定雾水中水溶 性离子成分, 包括 $\mathrm{Na}^{+} 、 \mathrm{NH}_{4}^{+} 、 \mathrm{~K}^{+} 、 \mathrm{Mg}^{2+} 、 \mathrm{Ca}^{2+}$ 、 $\mathrm{Cl}^{-} 、 \mathrm{Br}^{-} 、 \mathrm{NO}_{3}{ }^{-} 、 \mathrm{SO}_{4}{ }^{2-} 、 \mathrm{~F}^{-} 、 \mathrm{NO}_{2}^{-} 、 \mathrm{C}_{2} \mathrm{O}_{4}{ }^{2-}$, 检测方 法见孙玉等(2015). 需要指明, 受限于雾水采样需要人 工操作, 观测时无法将采样点设置于热带雨林内部的 无人区, 故本次观测所设置的雾水采样点位于热带雨 林的边缘(距离预仑镇约 $1 \mathrm{~km}$ ), 采样结果受到一定程度 人为活动的影响.

同时，我们使用雾滴谱仪FM-120(Fog Monitor， 


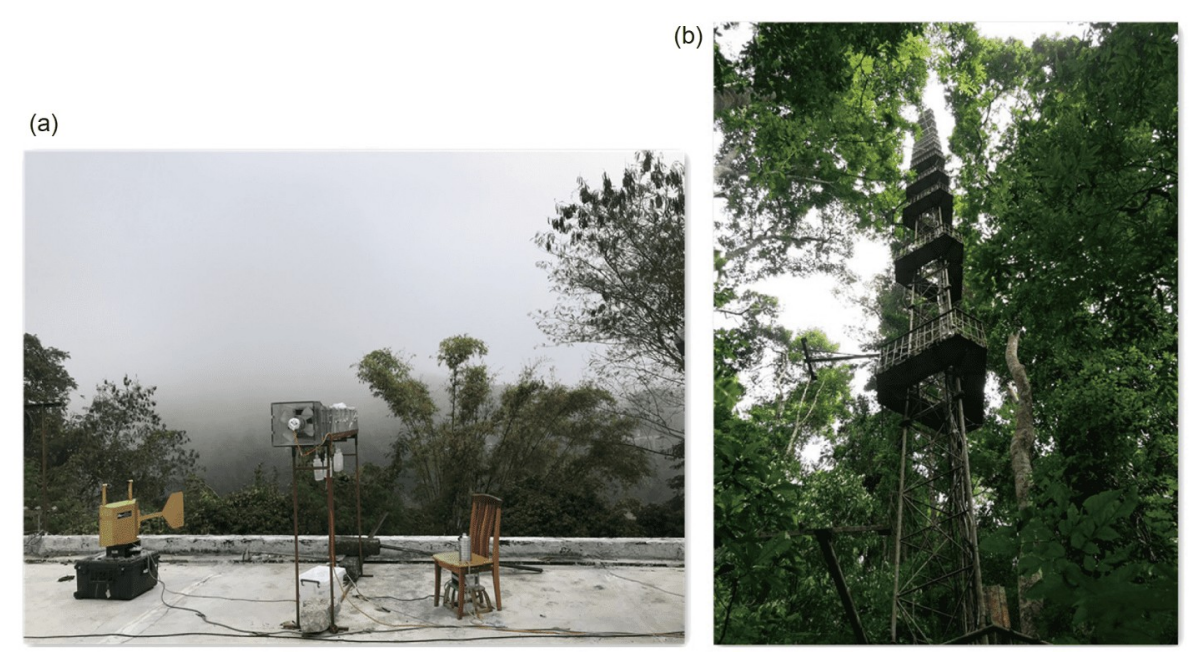

图 1 雾水化学采集点(a)和雾微物理观测点(b)的照片

model 120, DMT公司)连续测量雾的微物理特征. FM120 基于光散射原理，当粒子通过激光束时，通过测量 穿过景深区的粒子所产生的散射光来获得粒子的尺 寸及数目信息; 共分 30 档, 可测量直径 $(D)$ 范围为 $2 \sim 50 \mu \mathrm{m}$ 的雾滴谱分布，采样频率为 $1 \mathrm{~Hz}$. 观测前，使 用单分散的直径为 $30.1 \mu \mathrm{m}$ ，折射率为 1.51 的标准玻璃 粒子标定FM-120, 通过调节光路, 令定标后的峰值出 现在 $26 \mu \mathrm{m}$, 进而保证雾滴谱测量结果的可靠性(Spiegel等，2012). 雾滴谱的观测点位于植物园以西约 $10 \mathrm{~km}$ 国家级自然保护区内的热带季节雨林综合观测 场 $\left(21^{\circ} 55^{\prime} 39^{\prime \prime} \mathrm{N}, 101^{\circ} 15^{\prime} 55^{\prime \prime} \mathrm{E}\right.$, 海拔高度 $750 \mathrm{~m}$; 隶属中 国生态系统观测研究网CERN和中国通量研究网络 China FLUX的基础观测站点), FM-120架设于观测场 内观测铁塔上(塔高 $72 \mathrm{~m}$, 如图 $1 \mathrm{~b}$ 所示), 其架设高度为 $48.8 \mathrm{~m}$, 冠层高度约为 $35 \mathrm{~m}$ (Song 等, 2017). 观测点距离 最近的村寨居民生活点约为 $5 \sim 10 \mathrm{~km}$ ，位于热带雨林 区内部, 具有代表性.

此外，在植物园内架设宽范围粒径谱仪WPS1000XP(Wide-Range Particle Spectrometer, model $1000 X P, M S P$ 公司), 测量粒径范围在 $10 \mathrm{~nm} \sim 10 \mu \mathrm{m}$ 的气 溶胶数谱, 分 72 档, 每 $5 \mathrm{~min}$ 完成一次全谱扫描. 在WPS$1000 \mathrm{XP}$ 进气口之前连接装有变色硅胶干燥剂的 TSI3062气溶胶扩散干燥管，以保证进入WPS-1000XP 的气溶胶样品的相对湿度低于 $40 \%$. 本次观测研究中 还使用湍流、气象要素和大气辐射的观测结果，其观 测仪器及架设地点等信息见表1.

\section{2 方法}

根据FM-120测量的雾滴谱 $\left(N_{f}(D)\right)$ 数据, 计算雾滴 数浓度 $\left(N_{f}\right)$ 、算术平均直径 $(M D)$ 、体积平均直径 $(M V D)$ 、液态含水量 $(L W C)$ 、滴谱标准差 $(\sigma)$, 以及相 对离散度 $(\varepsilon)$ :

$N_{f}=\int N_{f}(D) \mathrm{d} D$,

$M D=\int N_{f}(D) \times D \mathrm{~d} D / N_{f}$,

$M V D=\left(\int N_{f}(D) \times D^{3} \mathrm{~d} D / N_{f}\right)^{1 / 3}$,

$L W C=\int \frac{\pi}{6} \rho_{w} \times N_{f}(D) \times D^{3} \mathrm{~d} D$,

$\sigma=\left(\int N_{f}(D) \times(D-M D)^{2} \mathrm{~d} D / N_{f}\right)^{1 / 2}$,

$\varepsilon=\sigma / M D$

其中, $D$ 表示每一档的雾滴直径, $\rho_{w}$ 表示液态水密度 (取 $\left.1 \mathrm{~g} \mathrm{~cm}^{-3}\right)$, 上述积分范围均为 $2 \sim 50 \mu \mathrm{m}$.

依据 $\kappa$-Köhler方程(Petters和Kreidenweis, 2007), 并 参考Shen等(2018)和Mazoyer等(2019)的计算方法，使 用同时刻测量的雾滴谱和干气溶胶谱以及假定的气溶 胶吸湿性因子 $(\kappa)$ 计算雾中有效过饱和度 $(S S)$. 本质上, 雾滴是在特定过饱和度条件下气溶胶活化的产物；因 而当已知气溶胶和雾滴的信息，可间接计算出过饱和 度. 算法流程如图2所示. 从 $\kappa$-Köhler方程可推导出活 化滴的临界活化直径 $\left(D_{c}\right)$ 与干气溶胶的临界活化直径 $\left(D_{a}\right) 、 \kappa$ 和温度 $(T)$ 的关系: 
表 1 观测仪器清单

\begin{tabular}{cccc}
\hline 仪器型号 & 厂商 & 观测项目 & 架设位置 \\
\hline FM-120 & DMT, 美国 & 雾滴谱, 粒径范围 $2 \sim 50 \mu \mathrm{m}$ & 铁塔 \\
CASCC-3stage & CSU, 美国 & 雾水分级采集 & 植物园 \\
WPS-1000XP & MSP, 美国 & 气溶胶谱, 粒径范围 $10 \mathrm{~nm} 10 \mu \mathrm{m}$ & 植物园 \\
CSAT3 & Campbell Sci, 美国 & 三维超声风速 & 铁塔 \\
HMP45C & Vaisala, 芬兰 & 温度和湿度 & 铁塔 \\
A100R & Vector Instruments, 英国 & 水平风速风向 & 铁塔 \\
NNR4 & Kipp \& Zonen, 荷兰 & 辐射通量 & 植物园 \\
DDS-11A & 上海雷磁创益, 中国 & EC, 0 10mS cm & 植物园 \\
Metrohm 827 & Metrohm, 瑞士 & pH, $0 ~ 14$ & 植物园 \\
\hline
\end{tabular}

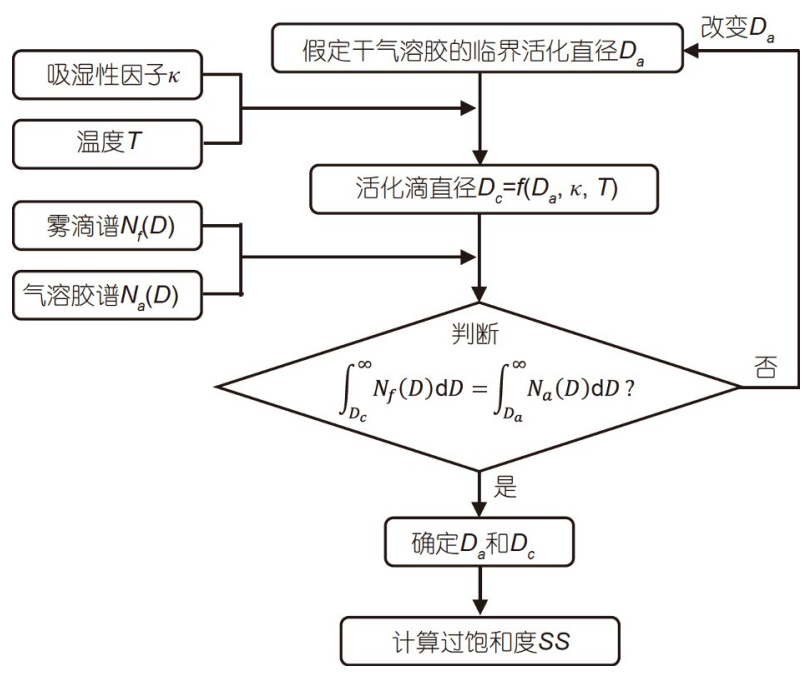

图 2 过饱和度计算流程

$D_{c}=\left(\frac{3 \kappa D_{a}^{3}}{A}\right)^{1 / 2}$,

其中,

$$
A=\frac{4 \sigma_{\mathrm{s} / 2} M_{w}}{R T \rho_{w}},
$$

式中, $\sigma_{\mathrm{s} / \mathrm{a}}$ 为液滴表面张力(假定为纯水, $0.0728 \mathrm{~N} \mathrm{~m}^{-2}$ ), $M_{w}$ 为水的摩尔质量, $R$ 为气体常数, $A$ 可视为 $T$ 的函数 (Seinfeld和Pandis, 2016). 首先假定一个 $D_{a}$, 根据式 (7a), 在 $T$ 和 $\kappa$ 已知时, 可计算出 $D_{a}$ 对应的 $D_{c}$. T使用FM120 实时测量的环境大气温度; 参考亚马孙热带雨林地 区气溶胶吸湿性的测量结果(AMAZE-08, Pöschl等, 2010)， $\kappa$ 假定为 0.15 . 这样设定 $\kappa$ 的可行性和合理性在 于: 观测点同属于热带雨林地区, 排放源相似; 该地区 雾中有着相对较高的 $S S$ (详见后文), 随着 $S S$ 增加, $S S$ 对 $\kappa$ 的敏感性减弱(Shen等, 2018); 对于气溶胶的活化能 力, 气溶胶粒径尺寸的重要性高于其化学组分(Dusek 等, 2006). 得到 $D_{a}$ 与 $D_{c}$ 的对应关系后, 分别以 $D_{c}$ 与 $D_{a}$ 为积分下限积分雾滴谱和干气溶胶谱, 若雾滴谱的积 分结果大于气溶胶谱的积分结果, 则减小 $D_{a}$, 反之则 增加 $D_{a}$, 理论上直至二者相等或误差在可接受范围内, 即可确定 $D_{a}$ 与 $D_{c}$. 在实际计算中, 我们的做法是以 72 档 气溶胶谱的每档中心直径 $D_{a}$ 由大到小做循环, 找到在 上一个循环中雾滴谱积分大于气溶胶谱积分, 而在下 一个循环中异号时对应的两个 $D_{a}$, 通过插值得到积分 相等时的 $D_{a}$, 后计算得到 $D_{c}$. 当 $S S$ 较大时, 会出现 2 $50 \mu \mathrm{m}$ 完整雾滴谱的积分值仍大于干气溶胶谱反向 积分至 $D_{a}\left(D_{c}=2 \mu \mathrm{m}\right)$ 的积分值, 此时令干气溶胶谱反向 积分直至等于完整雾滴谱的积分值, 从而找到 $D_{a}$ 及 $D_{c}$. 然后根据 $D_{c}$ 与临界过饱和度 $\left(S S_{c}\right)$ 的反比例关系(Wang Y等, 2019a):

$S S_{c}=\frac{200 \mathrm{~A}}{3 D_{c}}$,

便可计算得到 $S S$. 需要指明, 该算法忽略了碰并等非绝 热过程, 仅考虑活化和凝结增长的绝热过程. 若考虑碰 并过程造成的 $N_{f}$ 减少, 则实际有效过饱和度应高于此 计算值.

单位质量的大气湍流动能 $(T K E)$ 和摩擦速度 $\left(u_{*}\right)$ 使 用三维超声风温仪测量的风速计算得到:

$$
\begin{aligned}
& \overline{T K E}=\frac{1}{2}\left(u^{\prime 2}+v^{\prime 2}+w^{\prime 2}\right), \\
& u_{*}=\left[\left(-\overline{u^{\prime} w^{\prime}}\right)^{2}+\left(-\overline{v^{\prime} w^{\prime}}\right)^{2}\right]^{0.25},
\end{aligned}
$$

其中, $u^{\prime}$ 和 $v^{\prime}$ 为水平风速脉动量, $w^{\prime}$ 为垂直风速脉动量. 
三维超声风温仪与雾滴谱仪的架设位置相同，距地 $48.8 \mathrm{~m}$.

由于缺少能见度的观测，参考入云判据 $(\mathrm{Lu}$ 等， 2013; Wang Y等, 2019b; Gao等, 2020), 本文以 $N_{f}$ 大于 等于 $10 \mathrm{~cm}^{-3}$ 且 $L W C$ 大于等于 $0.001 \mathrm{~g} \mathrm{~m}^{-3}$ 作为雾判据, 从 微物理的角度判定雾过程. 据此, 自2019年12月2日至 2020年2月26日，我们使用FM-120共观测到20场雾过 程(其中 2019 年12月9日15:34至12月15日10:02和2019 年12月29日22:35至2020年1月7日02:03因设备故障或 铁塔断电而缺测)，累计获取 114305 个雾滴谱资料，详 见表2. 同时, 此次试验中我们共采集到 37 个雾水样品, 样品的分级分布不均匀, 其中 $73 \%$ 为 1 级样品 (27个), $24 \%$ 为 2 级样品 $(9$ 个), 3 级样品仅采集到 1 个，占 $3 \%$. 西 双版纳雾水样品的分级分布与以往我们在庐山和南京 用CASCC-3stage的测量结果不同. 2016年冬季在庐山 的观测中, 雾水样品趋近于三级均匀分布, 1 级、 2 级和
3 级的样品比例分别为 $33 \% 、 33 \%$ 和 $34 \%$ (胡春阳等, 2019)；2013年冬季在南京的一次强浓雾过程中，三级 的样品比例分别为 $35 \%$ 、35\%和30\%(康博识等, 2017). 雾水样品分级分布在本质上是由雾滴粒径谱分布决 定. 图3为平均雾滴数浓度谱和质量浓度谱分布，由图 可见，雾滴谱在直径大于 $22 \mu \mathrm{m}$ 的大粒径段仍存有较高 的 $N_{f}$, 从而导致质量谱在Stage_1出现峰值. FM-120与 CASCC-3stage的测量结果具有一致性，可佐证二者测 量结果的可靠性.

\section{3 结果与讨论}

\section{1 雾的形成机制与理化特征}

根据这20场雾的生消时间，统计得到该地区冬季 雾发生频率的日变化，如图4所示. 西双版纳热带雨林 地区雾多于夜间或清晨生成, 正午前消散; 雾出现频率

表 2 2019年冬季西双版纳热带雨林地区探测试验之雾过程清单 ${ }^{a)}$

\begin{tabular}{|c|c|c|c|c|c|c|c|c|c|}
\hline 序号 & 雾生时间 & 雾消时间 & $\begin{array}{c}\text { 雾样品数 } \\
\text { (个) }\end{array}$ & $\begin{array}{c}\text { 雾时间占比 } \\
(\%)\end{array}$ & $\begin{array}{c}\bar{N}_{f} \\
\left(\mathrm{~cm}^{-3}\right)\end{array}$ & $\begin{array}{r}\overline{M V D} \\
(\mu \mathrm{m})\end{array}$ & $\begin{array}{l}\overline{L W C} \\
\left(\mathrm{~g} \mathrm{~m}^{-3}\right)\end{array}$ & $\bar{\varepsilon}$ & $\begin{array}{l}\overline{S S} \\
(\%)\end{array}$ \\
\hline 1 & 2019-12-05 06:02 & 2019-12-05 09:52 & 550 & 4 & 40 & 5.8 & 0.004 & 0.25 & - \\
\hline 2 & 2019-12-05 18:15 & $2019-12-05$ 23:42 & 1169 & 6 & 48 & 5.4 & 0.004 & 0.50 & 0.075 \\
\hline 3 & 2019-12-06 04:23 & 2019-12-06 08:30 & 9521 & 64 & 58 & 15.7 & 0.117 & 0.76 & 0.079 \\
\hline 4 & 2019-12-07 07:40 & 2019-12-07 10:19 & 8609 & 90 & 65 & 14.1 & 0.096 & 0.69 & 0.092 \\
\hline 5 & 2019-12-15 10:02 & 2019-12-15 11:12 & 3514 & 84 & 82 & 12.9 & 0.093 & 0.65 & 0.081 \\
\hline 6 & 2019-12-16 07:21 & 2019-12-16 10:30 & 8919 & 79 & 51 & 14.9 & 0.089 & 0.63 & 0.066 \\
\hline 7 & 2019-12-17 06:50 & 2019-12-17 10:56 & 13307 & 90 & 55 & 17.0 & 0.141 & 0.71 & 0.069 \\
\hline 8 & 2019-12-18 07:17 & 2019-12-18 11:09 & 12534 & 90 & 44 & 19.0 & 0.157 & 0.65 & 0.069 \\
\hline 9 & 2019-12-21 10:12 & 2019-12-21 10:20 & 75 & 16 & 19 & 13.9 & 0.027 & 0.64 & 0.041 \\
\hline 10 & 2019-12-22 08:35 & 2019-12-22 08:53 & 568 & 53 & 43 & 13.5 & 0.055 & 0.65 & 0.063 \\
\hline 11 & 2019-12-23 08:17 & 2019-12-23 09:30 & 2402 & 55 & 39 & 18.8 & 0.136 & 0.72 & 0.072 \\
\hline 12 & 2019-12-26 08:15 & 2019-12-26 10:21 & 5680 & 75 & 60 & 13.7 & 0.080 & 0.69 & 0.077 \\
\hline 13 & $2019-12-27$ 22:04 & $2019-12-28$ 11:07 & 5692 & 12 & 54 & 6.3 & 0.007 & 0.28 & 0.061 \\
\hline 14 & 2019-12-28 18:59 & 2019-12-29 09:22 & 4499 & 9 & 62 & 6.0 & 0.007 & 0.27 & 0.061 \\
\hline 15 & 2020-01-07 10:01 & 2020-01-07 10:06 & 94 & 31 & 25 & 11.3 & 0.019 & 0.78 & - \\
\hline 16 & 2020-01-09 08:38 & 2020-01-09 10:12 & 3123 & 55 & 72 & 13.1 & 0.084 & 0.68 & - \\
\hline 17 & 2020-01-10 07:06 & 2020-01-10 10:38 & 9758 & 77 & 62 & 15.8 & 0.129 & 0.63 & - \\
\hline 18 & 2020-01-14 07:44 & 2020-01-14 10:24 & 8285 & 86 & 59 & 17.0 & 0.151 & 0.71 & - \\
\hline 19 & 2020-02-10 18:46 & 2020-02-11 11:39 & 15038 & 25 & 46 & 12.8 & 0.050 & 0.50 & - \\
\hline 20 & 2020-02-25 05:11 & $2020-02-25 \quad 08: 48$ & 968 & 7 & 44 & 10.3 & 0.025 & 0.61 & - \\
\hline \multicolumn{4}{|c|}{ 平均 } & 65 & 55 & 14.5 & 0.10 & 0.62 & 0.073 \\
\hline
\end{tabular}

a) $\bar{N}_{f}$ 为平均雾滴数浓度, $\overline{M V D}$ 为平均体积平均直径, $\overline{L W C}$ 为平均液态水含量, $\bar{\varepsilon}$ 为平均滴谱离散度, $\overline{S S}$ 为雾中平均过饱和度 


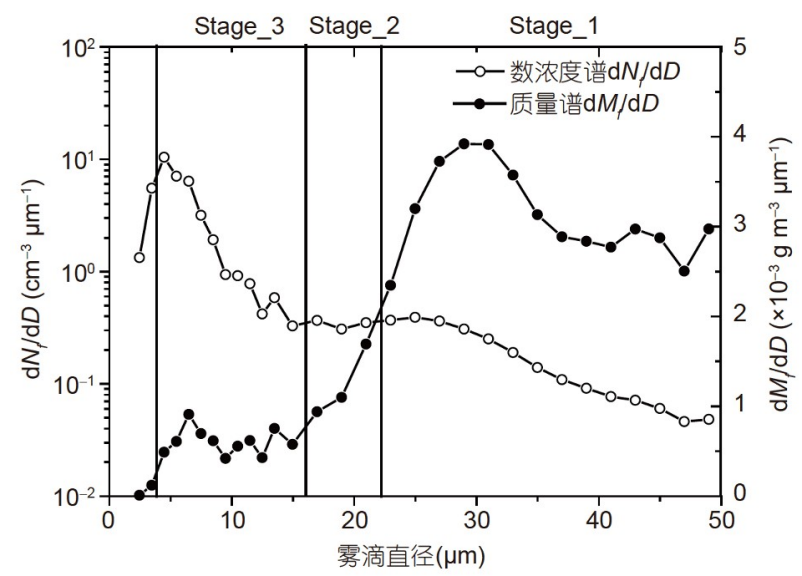

图 32019 年冬季西双版纳热带雨林地区辐射雾的平均数 浓度谱和质量谱分布

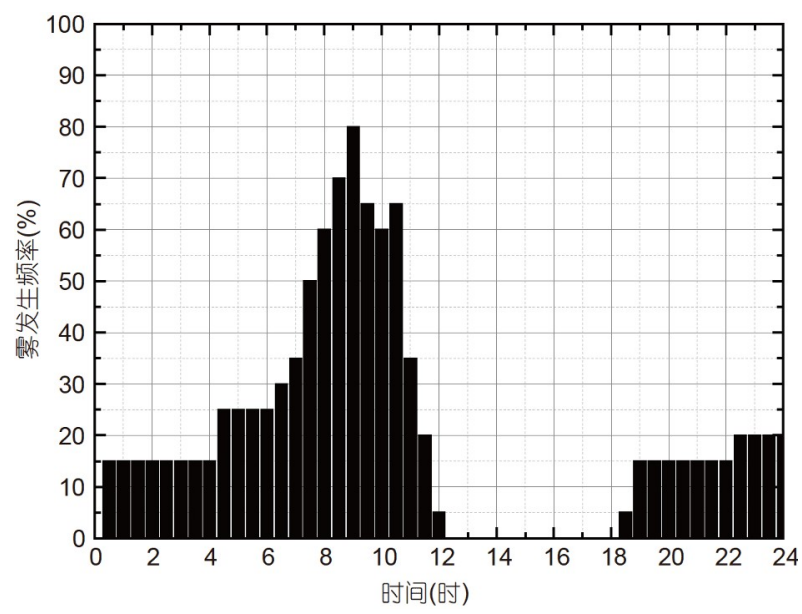

图 4 2019年冬季西双版纳热带雨林地区雾发生频率的时 间分布

的峰值位于上午 7 点 10 点(北京时间). 该地区雾的生 消时间符合典型辐射雾的特征(李子华，2001; Niu等, 2010；Li等，2019). 图5统计了该地区2019年冬季气象 要素和湍流特征的平均日变化, 进一步讨论该地区雾 的生消机制. 净辐射通量为上行长波和下行短波辐射 通量之和，夜间长波辐射冷却降温，令液滴表面饱和 水汽分压降低，大气相对湿度升高. 随着夜间长波辐 射冷却的进行, 大气温度逐渐接近甚至低于露点温度, 则大气中的水汽逐渐达到饱和甚至过饱和状态，此时 大粒径和强吸湿性的气溶胶率先活化形成雾滴并开始 凝结增长, 辐射雾就此形成. 在夜间, 风切变是产生湍 流的主要动力. 湍流令夜间辐射降温作用自下而上发 展, 形成逆温层, 随后雾在其中逐渐形成与发展. 日出
后, 太阳短波辐射增强, 净辐射通量逐渐由负转正, 大 气温度逐渐升高. 一方面, 大气增温导致饱和水汽分压 增加, 湿度减小, 促进雾滴蒸发; 另一方面, 大气热能与 动能相互转换, 大气增温激发湍流. 而湍流对雾的影响 具有两面性, 适当强度的湍流能够扩展雾层和冷却层 的范围从而促进雾的发展; 但过强的湍流会加速雾与 干空气的混合从而导致雾的消散，或抬升雾层而形成 低云(Rodhe, 1962; Barker, 1977). 摩擦速度可用于度 量湍流动量的垂直向输送能力, 结合西双版纳冬季雾 的生消时间与摩擦速度的日变化规律，我们发现当摩 擦速度大于 $0.2 \mathrm{~m} \mathrm{~s}^{-1}$ 时, 该地区不会出现雾, 这与Román-Cascón等(2016)在荷兰Cabauw大气研究实验站的 观测结果相同. 此外, 在热带雨林地区, 森林植被下垫 面对雾的影响不可忽略. 在相对干燥的冬季, 森林植被 的蒸腾作用所释放出的水汽是森林生态系统中重要的 水汽源，其蒸发量等同于同面积水体的蒸发量(周淑贞 和束昫, 1994). 其次, 森林对风速具有衰减作用, 利于 辐射雾的形成与维持. 最后, 相比于污染地区, 森林内 较低的气溶胶浓度减少大气相对湿度和过饱和度因气 溶胶吸湿增长和液滴凝结增长造成的损失(Lathem和 Nenes, 2011), 从而有利于活化过程的发生和雾的形成.

表2中统计这20场雾的生消时间、时间连续性和 微物理特征. 这里的时间连续性是指，在每次雾过程 中, 判定为雾的时间占整个过程持续时间的百分比, 比值越大表示越连续. 我们发现雾持续时间的波动性 很大，从几分钟(如个例 9 和 15 )至十几个小时(如个例 13、14和19)不等; 并且雾在时间上的连续性亦有很大 差异(雾时间占比4 90\%). 这表明热带雨林地区的辐射 雾并非是在一个持续稳定的层结环境中出现和发展 的. 当同时满足有利于雾形成和维持的边界层条件、 充沛的湿度条件以及适当的凝结核浓度时，会形成稳 定的雾层结构, 此时雾不易因局地热力或动力扰动而 消散，从而雾在时间上更连续，有更长时间的凝结增 长, 雾发展得更深厚; 反之, 在不利的层结以及较强的 动力热力扰动下, 雾在时间上更容易中断, 雾的强度减 弱. 由图6可见，雾时间占比和 $L W C$ 之间存在显著的正 相关关系.

表3统计了不同地区不同类型雾的微物理特征. 相 比于其他雾的观测结果，2019年西双版纳辐射雾的特 征为: $N_{f}$ 低 (均值为 $\left.55 \mathrm{~cm}^{-3}\right)$, 雾滴粒径大 $(M V D$ 均值可 达到 $14.5 \mu \mathrm{m}), L W C$ 较高(均值为 $0.1 \mathrm{~g} \mathrm{~m}^{-3}$ ), 滴谱相对谱 

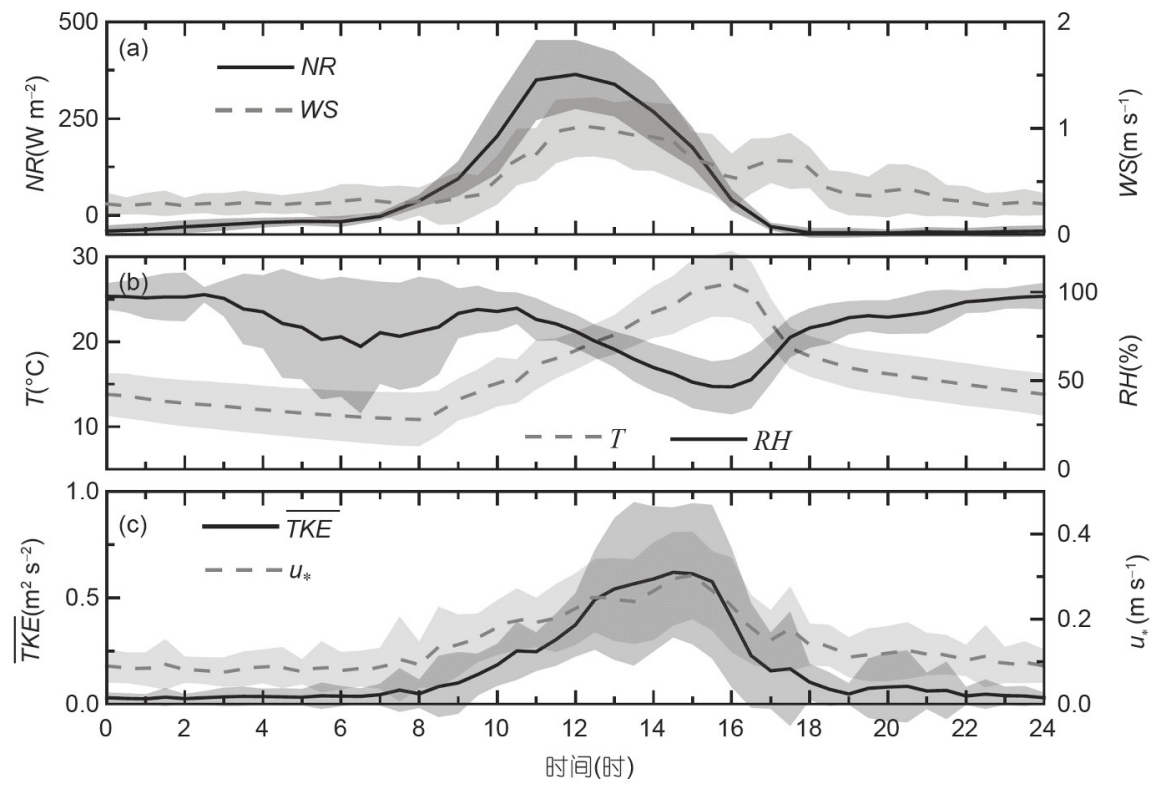

图 5 2019年冬季西双版纳热带雨林地区气象要素、大气辐射和湍流特征的平均日变化

$N R$ 为净辐射通量, $W S$ 为水平风速, $T$ 为环境温度, $R H$ 为相对湿度, $\overline{T K E}$ 为湍流平均动能, $u_{*}$ 为摩擦速度; 线段为平均值, 阴影为标准差

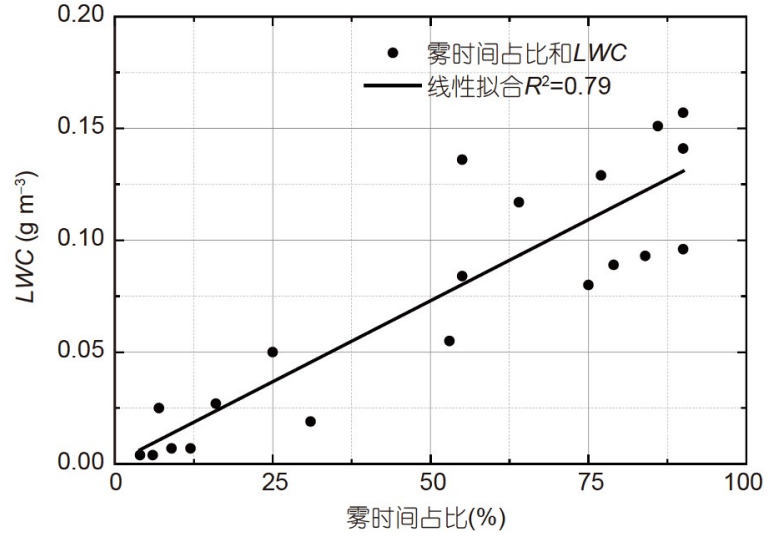

图 6 平均含水量 $(L W C)$ 与雾时间占比的关系

宽较窄 (平均 $\varepsilon$ 为 0.62 ), $S S$ 高(平均值为 $0.073 \%$ ). 与 1997 年冬季在西双版纳城郊地区观测到的辐射雾(黄玉生 等, 2000)相比, $L W C$ 几乎相同, 但 $N_{f}$ 显著减少, 雾滴粒 径增大. 造成这种变化的原因可能是: 相比于城郊, 热 带雨林地区大气中凝结核的浓度降低，根据气溶胶第 一间接效应(Twomey, 1974, 1977), 在相似的水汽条件 下，更少的凝结核数目意味着有更少且更大的雾滴形 成. 在后文对雾水化学组分的分析中，我们亦发现雾 水中总化学离子浓度降低. 因此，气溶胶及凝结核数 目的差异可能是导致雾理化特征差异的主要原因. 与
其他地区不同类型的云雾相比，如武清和南京污染区 的辐射雾(Shen等, 2018; 王元等, 2019), 庐山和南岭的 山地雾(吴兄等, 2007; Wang T S等, 2019), 热带雨林地 区的辐射雾同样表现出较低的 $N_{f}$ 和更大的雾滴粒径. 一方面，热带雨林地区的大气环境受人类活动的影响 较小，属于相对清洁地区，凝结核数浓度背景值偏低; 另一方面, 森林生态系统具有过滤和净化大气的作用, 林木的枝叶表面可吸附大气中的颗粒物和气态前体物 (薛永刚等, 2013), 进一步降低凝结核浓度.

2019年和1997年西双版纳地区雾水的化学组分特 征见表4. 2019年雾水的 $\mathrm{pH}$ 变化范围为6.96 8.06, 体积 加权平均值为 7.64 , 呈碱性; $E C$ 的变化范围为 $0.04 \sim 0.30 \mathrm{mS} \mathrm{cm}^{-1}$, 体积加权平均值为 $0.07 \mathrm{mS} \mathrm{cm}^{-1}$. 相比于 1 级采集到的大雾滴, 2 级和 3 级采集到的小雾 滴中总离子浓度更高, 说明化学组分在小雾滴富集. 雾水中化学组分的尺度依赖性分布特征已在多地区被 观测到(Ogren等，1992; Collett Jr.等，1999; Raja等， 2008; 张鸿伟等，2019)，其机理与气溶胶的核化过程 以及雾滴形成后对气体的吸收和液相化学反应相关 (Lu等, 2010; 胡春阳等, 2019); 且雾滴越小, 雾滴总表 面积越大( $L W C$ 固定时), 对气体的吸收率越高. 与 1997 年11月西双版纳城郊地区 (预养)采集的雾水相比 $\left(\mathrm{pH}=8.34, E C=0.25 \mathrm{mS} \mathrm{cm}^{-1}\right.$; 朱涁等, 2000), 2019年冬 
季热带雨林地区采集到的雾水的碱性程度减弱，电导 率减小；2019年雾水中总离子浓度显著降低，其中阳 离子当量浓度降低了 $60 \%$, 阴离子当量浓度降低了 $58 \%$. 此外, 我们发现西双版纳地区检测的雾水中阴阳 离子浓度不平衡，阳离子与阴离子的平均当量浓度之 比为 1.8 , 这表明存在某些阴离子的漏测. 一般认为是 忽略了 $\mathrm{HCO}_{3}^{-}$的缘故，当 $\mathrm{pH}>5.6$ 时, $\mathrm{HCO}_{3}{ }^{-}$对阴粒子贡 献不可被忽略，且其贡献随 $\mathrm{pH}$ 增加而增大(唐孝炎等, 2006).

图7给出2019年和1997年西双版纳地区冬季辐射
雾的化学组成. 需要指出, 这两场试验中雾水化学组成 的观测结果均因采样点靠近城镇而受到一定程度人为 活动的影响. 相比于1997年检测的雾水化学组分, 2019 年雾水 (三级雾水体积加权平均结果, 即表4中S_2019) 中 $\mathrm{NH}_{4}{ }^{+} 、 \mathrm{~K}^{+} 、 \mathrm{Cl}^{-}$和 $\mathrm{NO}_{3}{ }^{-}$当量浓度占比显著增加, $\mathrm{Ca}^{2+} 、 \mathrm{SO}_{4}{ }^{2-} 、 \mathrm{~F}^{-}$占比显著减少, $\mathrm{Na}^{+} 、 \mathrm{Mg}^{2+} 、 \mathrm{NO}_{2}^{-}$占 比无显著变化. 在2019年和1997年西双版纳地区的雾 水中, $\mathrm{Ca}^{2+}$ 始终为阳离子中占比最高的; 而在阴离子占 比中, $\mathrm{Cl}^{-}$取代 $\mathrm{SO}_{4}{ }^{2-}$ 成为占比最高的离子. 这在一定程 度上受到雾水采样点位于热带雨林边缘的影响. $\mathrm{Ca}^{2+}$

表 3 不同地区不同类型雾的微物理特征比较

\begin{tabular}{|c|c|c|c|c|c|}
\hline 不同地区不同类型的雾观测 & $\bar{N}_{f}\left(\mathrm{~cm}^{-3}\right)$ & $\overline{M V D}(\mu \mathrm{m})$ & $\overline{L W C}\left(\mathrm{~g} \mathrm{~m}^{-3}\right)$ & $\bar{\varepsilon}$ & $\overline{S S}(\%)$ \\
\hline 2019年冬季西双版纳辐射雾 & 55 & 14.5 & 0.10 & 0.62 & 0.073 \\
\hline 1997年冬季西双版纳辐射雾 ${ }^{a)}$ & 223 & 9.9 & 0.11 & 0.86 & - \\
\hline 2017年冬季南京辐射雾b) & 567 & 8.5 & 0.18 & 0.70 & - \\
\hline 2009年冬季武清辐射雾c) & 563 & 9.7 & 0.27 & 0.64 & $<0.050$ \\
\hline 2011 2013年巴黎PAFOG辐射雾 ${ }^{d)}$ & 82 & - & - & - & 0.042 \\
\hline 2011 2013年巴黎PAFOG平流雾 ${ }^{\mathrm{d})}$ & 50 & - & - & - & 0.050 \\
\hline 2010年春季湛江海雾e) & 40 & 8.6 & 0.01 & - & - \\
\hline 2007年春季茂名海雾f) & 57 & 8.4 & 0.02 & - & - \\
\hline 2016和2017年冬季庐山山地雾g) & 158 & 8.7 & 0.07 & - & - \\
\hline 1998 2000年冬季南岭山地雾h) & 168 & 12.2 & 0.16 & - & - \\
\hline
\end{tabular}

a) 黄玉生等(2000); b) 王元等(2019); c) Shen等(2018); d) Mazoyer等(2019); e) 张舒婷等(2013); f) 黄辉军等(2009); g) Wang T S等(2019); h) 吴兑等 (2007). $\bar{N}_{f}$ 为平均雾滴数浓度, $\overline{M V D}$ 为平均体积平均直径, $\overline{L W C}$ 为平均液态水含量, $\bar{\varepsilon}$ 为平均滴谱离散度, $\overline{S S}$ 为雾中平均过饱和度

(a)
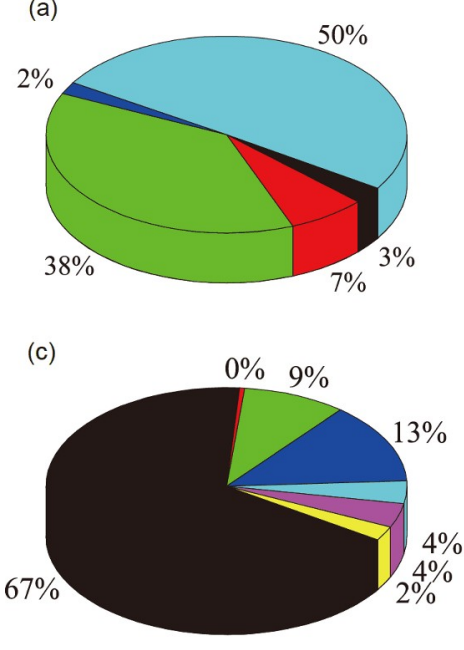

(b)

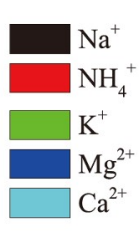

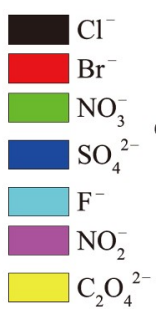

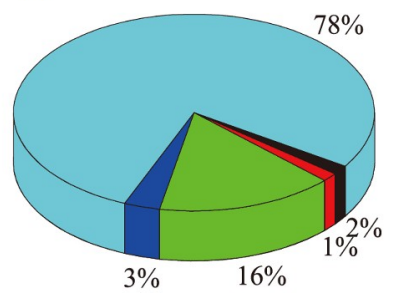

(d)

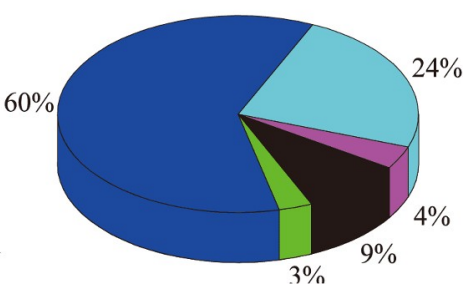

图 7 2019年和1997年西双版纳地区雾水中阴阳离子当量浓度占比分布

(a) 2019年雾水阳离子占比; (b) 1997年雾水阳离子占比; (c) 2019年雾水阴离子占比; (d) 1997年雾水阴离子占比. 其中1997年的结果引自朱彬 等(2000) 
主要来源为土壤侵蚀和建筑施工(Nieberding等, 2018), 其高占比表明局地雾水可能受到人为活动的影响; $\mathrm{Cl}^{-}$ 的高占比可能与当地村寨居民的生活排放相关，例如 燃烧会向大气中释放出氯盐含量极高的飞灰，造成氯 盐挥发(Jakob等, 1996; 王雷等, 2010). 当夜间辐射冷 却至空气过饱和时，含氯气溶胶充当云凝结核活化形 成雾滴，并且雾滴形成后进一步吸附大气中的 $\mathrm{Cl}^{-}$, 从 而在雾水中出现 $\mathrm{Cl}^{-}$的高占比.

\section{2 过饱和度与雾微物理过程}

过饱和度是制约雾形成与否的关键因子，亦是雾 形成后能否发展维持的重要因素. 其影响主要体现在 以下两个方面: 一是过饱和度控制气溶胶的活化过程, 影响雾滴的数目(Wang等, 2021); 二是过饱和度控制雾
滴的凝结增长速率，影响雾滴的大小 (Chen等，2016, 2018). 因而雾中过饱和度的分布直接决定了雾的微物 理特征. 因同一地区同一类型的雾过程, 在背景气溶胶 性质、水汽源汇、边界层特征以及形成机理上具备相 似性, 本节以2019年12月7日雾过程(个例4)为例，研究 过饱和度与雾微物理过程的关联.

如图8a所示，在此次雾过程前半段(07:40 09:00), $S S$ 在 $0.075 \sim 0.1 \%$ 之间起伏波动; 在后半段( $09: 00$ $10: 19), S S$ 出现峰值达 $0.16 \%$, 峰值过后 $S S$ 持续减小直 至此次雾消散. $D_{c}$ 与 $S S$ 之间为反比例关系, 在整个雾 过程中, $D_{c}$ 几乎均小于 $2 \mu \mathrm{m}$, 这意味着FM-120的测量 结果中几乎全部为活化滴，并且大部分测量中存在对 活化滴的漏测. 此次雾过程的平均环境温度为 $17.5^{\circ} \mathrm{C}$ (变化范围16.5 $18.0^{\circ} \mathrm{C}$ ), 由式(8)计算可知，当 $S S$ 大于

表 4 西双版纳地区雾水化学组成

\begin{tabular}{|c|c|c|c|c|c|c|c|c|c|c|c|c|c|c|c|c|c|}
\hline 样品 & $\mathrm{pH}$ & $E C$ & $\mathrm{Na}^{+}$ & $\mathrm{NH}_{4}^{+}$ & $\mathrm{K}^{+}$ & $\mathrm{Mg}^{2+}$ & $\mathrm{Ca}^{2+}$ & $\mathrm{Cl}^{-}$ & $\mathrm{Br}^{-}$ & $\mathrm{NO}_{3}^{-}$ & $\mathrm{SO}_{4}^{2-}$ & $\mathrm{F}^{-}$ & $\mathrm{NO}_{2}^{-}$ & $\mathrm{C}_{2} \mathrm{O}_{4}{ }^{2-}$ & $\sum+$ & $\Sigma-$ & $\Sigma^{+/} \Sigma_{-}^{-}$ \\
\hline S1_2019 & 7.64 & 0.07 & 20.2 & 56.5 & 307.1 & 15.3 & 397.7 & 307.9 & 2.1 & 39.6 & 59.4 & 16.4 & 18.3 & 10.5 & 796.8 & 454.2 & 1.8 \\
\hline S2_2019 & 7.18 & 0.22 & 120.3 & 55.1 & 135.2 & 66.6 & 1326.9 & 186.4 & 3.0 & 194.1 & 178.4 & 63.0 & 34.3 & 19.3 & 1704.0 & 678.6 & 2.5 \\
\hline S3_2019 & 7.36 & 0.19 & 457.9 & 101.3 & 348.7 & 130.3 & 1406.1 & 508.3 & 2.0 & 488.4 & 267.9 & 124.3 & 16.9 & 21.5 & 2444.3 & 1429.4 & 1.7 \\
\hline S_2019 & 7.64 & 0.07 & 22.9 & 56.7 & 306.5 & 16.1 & 407.5 & 308.3 & 2.1 & 42.6 & 61.0 & 17.2 & 18.4 & 10.6 & 809.7 & 460.2 & 1.8 \\
\hline S_1997 ${ }^{\text {a) }}$ & 8.34 & 0.25 & 31.9 & 28.3 & 320.1 & 64.8 & 1568.2 & 100.4 & - & 32.5 & 661.0 & 258.2 & 41.0 & - & 2013 & 1093 & 1.5 \\
\hline
\end{tabular}

a) 朱涁等(2000). 电导率 $E C$ 单位 $\mathrm{mS} \mathrm{cm}{ }^{-1}$; 体积加权平均当量浓度, 单位为 $m e q \mathrm{~L}^{-1}$; S1_2019、S2_2019和S3 2019分别表示2019采集的1 级、2级和3级雾水样品, S_2019和S_1997分别为2019年雾水体积加权平均结果和1997年的雾水结果
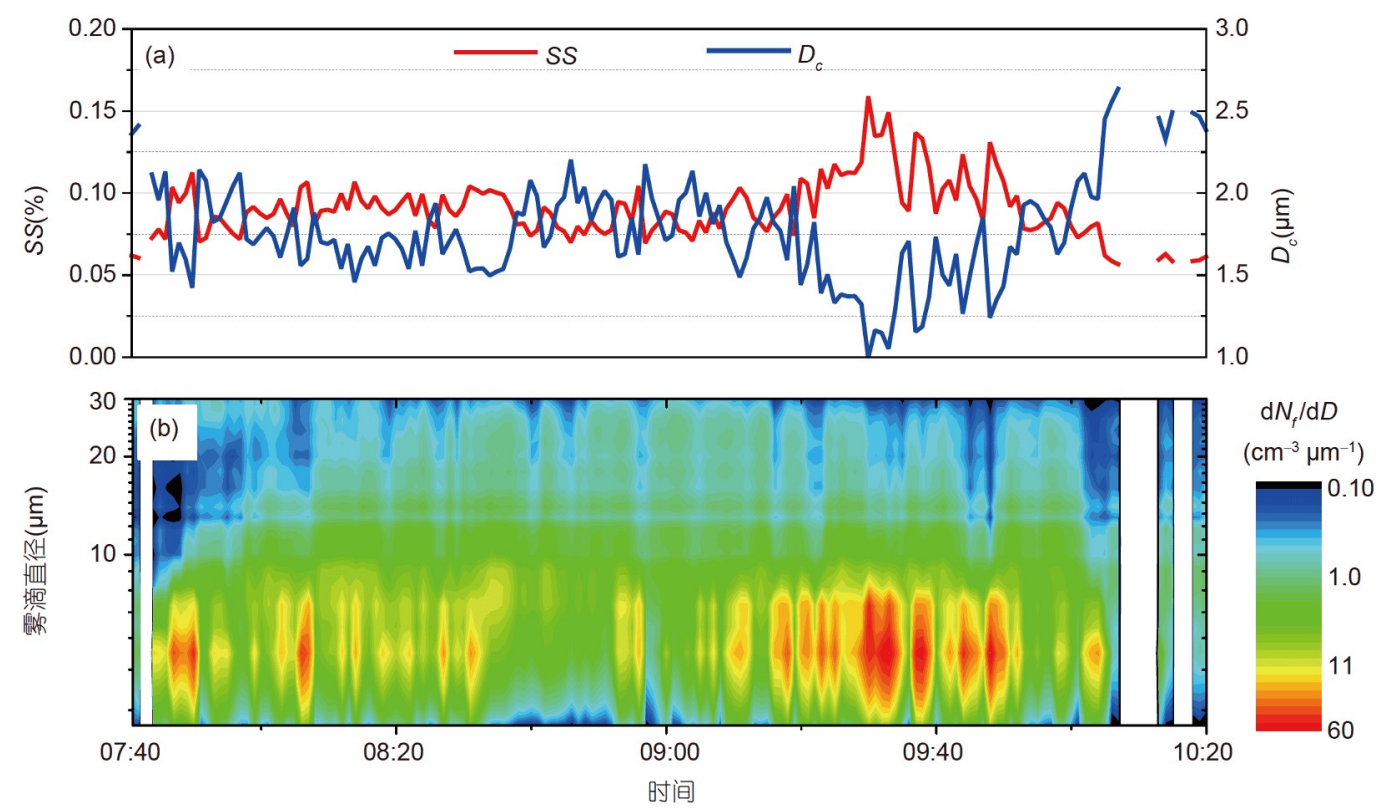

图 82019 年12月7日雾过程中过饱和度 $(S S)$ 、活化滴的临界活化直径 $\left(D_{c}\right)(a)$ 和雾滴谱 $(b)$ 的时间分布 
$0.073 \% ， D_{c}$ 小于 $2 \mu \mathrm{m}$ ，此时因FM-120量程限制而漏测 部分活化滴, 导致 $S S$ 计算结果的低估. 图 $8 \mathrm{~b}$ 为此次雾 过程的瞬时雾滴谱. 在雾过程的前半段, $S S$ 稳定在 $0.075 \sim 0.1 \%$ 之间波动时，由图 $8 \mathrm{~b}$ 可见，浓度在 $1 \sim 10 \mathrm{~cm}^{-3} \mu \mathrm{m}^{-1}$ (图中绿色区域)对应的最大直径由雾 初生时的不足 $10 \mu \mathrm{m}$, 发展至雾中期(09:00)时已达到 $30 \mu \mathrm{m}$ ，并且雾中期时小滴浓度亦出现低值，可见雾滴 谱表现出显著的向大滴方向平移并拓宽的特征．其在 物理机理上可视为雾滴群的凝结增长过程. 液滴的凝 结增长速率方程为

$\frac{\mathrm{d} D}{\mathrm{~d} t}=\frac{1}{D} \frac{S S-S S_{k}}{G}$,

其中， $t$ 为时间， $G$ 为凝结增长因子 (Lamb和Verlinde, 2011), 在本文分析中 $G$ 可假定是常数, $S S_{k}$ 为液滴表面 平衡过饱和度, 可由 $\kappa$-Köhler方程导出. 当环境 $S S$ 远大 于 $S S_{k}$ 时，粒径增长率取决于液滴粒径，随粒径增加而 减小, 小滴凝结增长速率快于大滴, 从而导致在一段增 长时间后, 滴谱右移增高变窄, 即凝结变窄现象(Wallace和Hobbs, 2006). 但当 $S S$ 接近于 $S S_{k}$ 时, $S S$ 与 $S S_{k}$ 的差 值决定粒径增长速率, 而大滴的 $S S_{k}$ 小, 差值更大, 此时 大滴增长速率快于小滴, 出现凝结拓宽现象(Chen等, 2018). 此次雾过程前半段中, 在较低SS条件下的雾滴 谱右移拓宽与上述凝结拓宽现象是一致的. 在此次雾 过程的后半段，因 $S S$ 的增加，持续性活化过程导致雾 滴谱中涌现出大量新活化的雾滴，集中分布于雾滴谱
的小粒径端. 但值得注意的是，雾滴谱并未在前半段 的基础上继续向大滴拓宽，反而在图 $8 \mathrm{~b}$ 中出现部分大 滴缺口. 凝结过程无法合理地解释这一现象，因为无 论凝结拓宽还是凝结变窄均不会导致大滴的消失. 雾 滴因凝结增长变大而导致的重力碰并以及因雾滴浓度 增加而促进的湍流碰并是更为合理的解释. 那么在这 一阶段，计算的 $S S$ 会因碰并过程导致的雾滴浓度减少 而进一步被低估. 假设因雾滴谱仪缺测小于 $2 \mu \mathrm{m}$ 活化 滴和碰并过程造成的对活化滴的低估占总雾滴数浓度 测量结果的 $20 \%$, 约为 $13 \mathrm{~cm}^{-3}$. 对于干气溶胶谱, $D_{c}$ $=2 \mu \mathrm{m}(S S=0.073 \%)$ 对应的临界 $D_{a}$ 为 $269 \mathrm{~nm}$, 此时 $13 \mathrm{~cm}^{-3}$ 活化滴数目的低估会导致临界 $D_{a}$ 被高估 $9 \%$, 进 而导致 $S S$ 被低估 $15 \%(S S=0.084 \%)$.

在图9中，进一步给出了 $S S$ 和 $N_{f}$ 以及 $M V D$ 的关系. 从概率密度函数 $(\mathrm{PDF})$ 分布图可见, $N_{f}$ 随 $S S$ 增加而增 加，为显著的正相关，这是因为更大的 $S S$ 会让更多更 小的气溶胶得以活化; $N_{f}$ 与 $S S$ 关系的标准差, 即每一 个 $S S$ 对应的 $N_{f}$ 值区间, 受限于气溶胶的性质, 包括气溶 胶粒子谱的形状和化学组分和混合态, 在本文中仅为 气溶胶粒子谱的影响. $S S$ 和 $M V D$ 之间表现为负相关关 系, 随着 $S S$ 增加, $M V D$ 逐渐减小并且收玫. 其物理机理 是气溶胶活化过程、雾滴凝结增长和碰并过程共同作 用的结果. 随着过饱和度的增加, 首先会发生持续性活 化过程导致滴谱中小粒径液滴占比的增加，导致雾滴 $M V D$ 的减小; 其次在过饱和条件下，雾滴的凝结增长

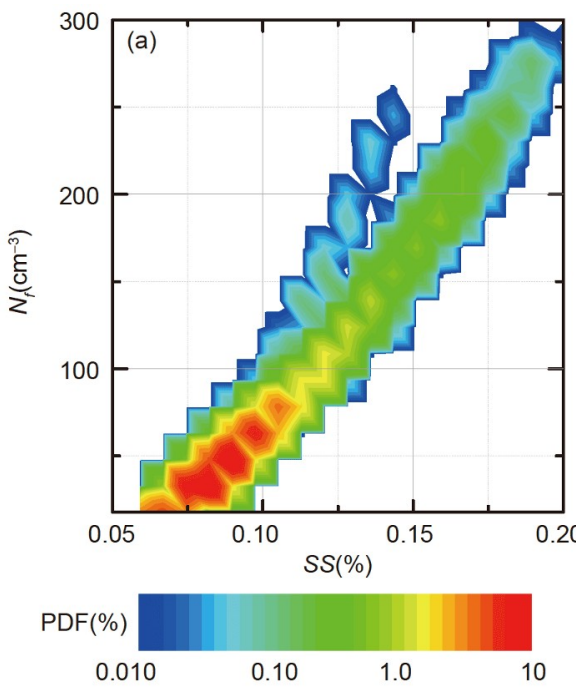

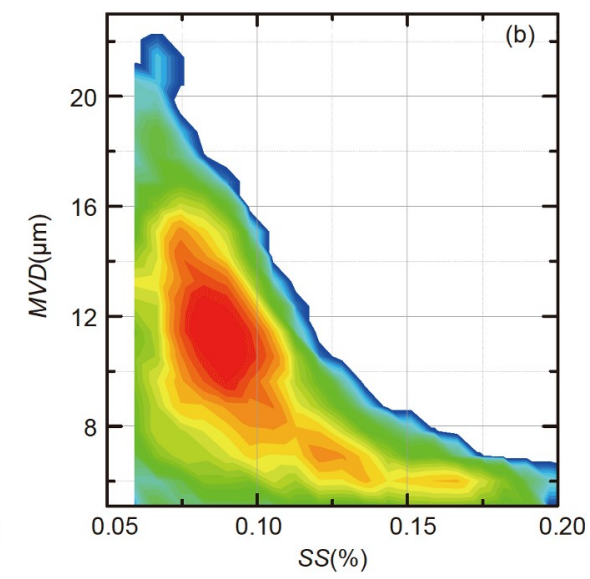

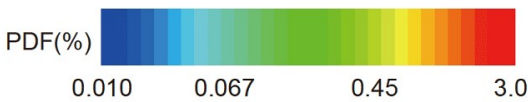

图 9 过饱和度 $(S S)$ 与雾滴数浓度 $\left(N_{f}\right)$ 和雾滴体积平均直径 $(M V D)$ 的概率密度函数分布

(a) 过饱和度 $(S S)$ 与雾滴数浓度 $\left(N_{f}\right)$ 的概率密度函数分布; (b) 过饱和度 $(S S)$ 与雾滴体积平均直径 $(M V D)$ 的概率密度函数分布 
过程会持续发生，导致雾滴 $M V D$ 的增大; 最后雾滴的 碰并导致大滴数目的减少，大滴在浓度谱中的占比进 一步下降，导致 $M V D$ 的减小. 显然当活化过程和碰并 过程造成的 $M V D$ 减小的效果大于凝结过程对增大 $M V D$ 的影响时，就会出现 $S S$ 和 $M V D$ 之间的负相关关 系. 为了衡量小雾滴在雾滴谱中所占的比例, 我们使 用 $\mathrm{Lu}$ 等 $(2020)$ 提出的雾滴谱中第一档 $(2 \sim 3 \mu \mathrm{m})$ 雾滴的 数目占所有雾滴数目的比例, 其与 $S S$ 的关系见图 10 . 随 着 $S S$ 的增加，第一档雾滴的数目占比确实如上述分析 所言, 表现出增加的趋势. 但值得注意的是, 第一档小 滴在较低 $S S$ 时, 也可以达到比较高的比例. 这是因为在 雾的初生阶段, 大气中 SS形成后, 气溶胶快速活化形成 雾滴, 此时处于凝结增长初始阶段, 雾滴谱集中于初始 活化形成的小雾滴端, 如图 $8 \mathrm{~b}$ 中雾初生阶段的滴谱.

\section{4 结论}

2019年冬季在西双版纳热带雨林地区开展了为 期 3 个月的辐射雾综合探测试验，通过对雾的生消机 理、理化特征及水汽过饱和度等研究，得到以下 结论.

该地区雾多于夜间生成, 于翌日正午前消散. 夜间 的长波辐射冷却结合森林下垫面蒸腾作用释放的大量 水汽和森林边界层内较低的气溶胶浓度, 形成高湿甚 至过饱和的大气环境, 同时夜间森林内微风的动力环 境，诱发湍流并形成逆温层，促进辐射雾的生成. 翌日 日出后, 湍流增强导致扩散和输送增强, 适度的湍流强 度利于扩展雾层和冷却层的范围而促进雾的发展，但 过强则会加速雾与干空气的混合从而导致雾的消散, 或抬升雾层而形成低云.

该地区辐射雾的微物理特征为：雾滴数浓度低, 雾滴粒径大, 液态含水量较高, 滴谱相对谱宽较窄, 过 饱和度高. 其化学特征为: 雾水呈弱碱性, 电导率低, $\mathrm{Cl}^{-}$和 $\mathrm{Ca}^{2+}$ 分别为雾水中阴、阳离子的最高占比, 且化 学组分在小滴富集. 与1997年冬季西双版纳城郊辐射 雾的探测结果(黄玉生等, 2000; 朱涁等, 2000; 濮梅娟 等, 2001)相比，两场试验中雾的理化特征存在显著差 异: $L W C$ 相近，但2019年热带雨林地区辐射雾的 $N_{f}$ 显 著减少, $M V D$ 增大, 且雾水的 $E C$ 和 $\mathrm{pH}$ 均降低; 在雾水 中, $\mathrm{Ca}^{2+}$ 始终为占比最高的阳离子, $\mathrm{Cl}^{-}$取代 $\mathrm{SO}_{4}{ }^{2-}$ 成为 占比最高的阴离子, 这与当地村寨居民的人为活动相

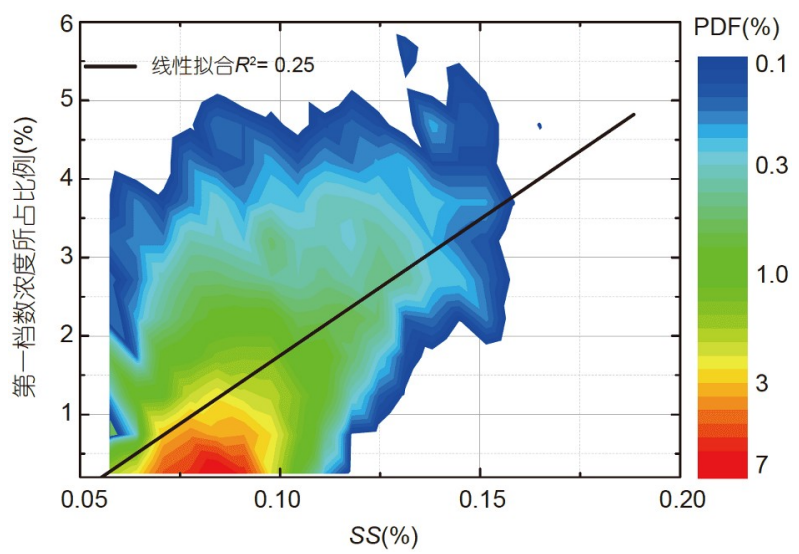

图 10 过饱和度 $(S S)$ 与雾滴谱中第一档数浓度所占比例的 概率密度函数分布

关. 需要指出的是, 本次试验中雾微物理观测点位于 雨林内部，能够准确反映雨林地区雾的微物理特征; 雾水采集受限于人工操作，观测点位于热带雨林区边 缘, 雾水化学的观测结果在一定程度上受到人为活动 影响.

根据 $\kappa$-Köhler理论，间接计算了雾中过饱和度分 布. 我们发现西双版纳热带雨林地区辐射雾中有着较 高的过饱和度分布，意味着雾滴谱测量结果中未活化 的雱粒很少，并会出现对活化滴测量不完全的现象. 在2019年12月7日雾过程个例中，雾发生的前半段雾 滴谱存在凝结拓宽现象; 由于过饱和度影响气溶胶活 化过程，过饱和度与 $N_{f}$ 之间为显著正相关关系; 因在 过饱和度增加的阶段，持续性活化及碰并过程造成雾 滴谱中小雾滴数目占比的增加, 造成过饱和度与 $M V D$ 之间存在负相关关系.

致谢中国科学院大气物理研究所张晓庆研究员帮助标 定仪器, 中国科学院热带森林生态学重点实验室杨东海 助理工程师协助开展试验，云南西双版纳森林生态系统 国家野外科学观测研究站提供常规气象数据, 在此一并 谨致谢忱.

\section{参考文献}

宫世贤, 凌升海. 1996. 西双版纳雾在减少. 气象, 22: 10-14

顾震潮. 1980. 云雾降水物理基础. 北京: 科学出版社

郭丽君, 郭学良, 方春刚, 朱士超. 2015. 华北一次持续性重度雾䨪天 气的产生, 演变与转化特征观测分析. 中国科学: 地球科学, 45: 
$427-443$

胡春阳, 柇曙先, 王小龙, 张鸿伟, 朱丹丹. 2019. 庐山2016年冬季三 级分档雾水化学特征. 气象学报, 77: 745-757

黄辉军, 黄健, 刘春霞, 袁金南, 吕卫华, 杨永泉, 毛伟康, 廖菲. 2009. 茂名地区海雾的微物理结构特征. 海洋学报, 31: 17-23

黄建平, 李子华, 黄玉仁, 黄玉生. 2000. 西双版纳地区雾的数值模拟 研究. 大气科学, 24: 821-834

黄玉仁, 黄玉生, 李子华, 陈宝君. 2000. 生态环境变化对雾的影响. 气象科学, 20: 129-135

黄玉生, 黄玉仁, 李子华, 陈宝君, 黄建平, 顾江新. 2000. 西双版纳冬 季雾的微物理结构及演变过程. 气象学报, 6: 715-725

康博识, 㚞曙先, 张悦, 李皓, 孙玉. 2017. 南京冬季持续性强浓雾天 气中三级分档雾水的理化特性分析. 气象学报, 75: 356-370

李子华. 2001. 中国近40年来雾的研究. 气象学报, 59: 616-624

李子华, 彭中贵. 1994. 重庆市冬季雾的物理化学特性. 气象学报, 52: $477-483$

刘文杰, 张一平, 李红梅, 段文平. 2004. 西双版纳热带季节雨林内雾 特征研究. 植物生态学报, 28: 264-270

陆春松, 牛生杰, 杨军, 刘新, 赵丽娟. 2010. 南京冬季一次雾过程宏 微观结构的突变特征及成因分析. 大气科学, 34: 681-690

吕晶晶, 牛生杰, 张羽, 徐峰. 2014. 湛江东海岛一次春季海雾的宏微 观结构及边界层演变特征. 气象学报, 72: 350-365

马友金金, 郭萍, 张一平, 李佑荣. 1999. 西双版纳地区气候变化与森林 片断化. 热带植物研究, 46: 262-269

牛生杰, 陆春松, 吕晶晶, 徐峰, 赵丽娟, 刘端阳, 岳岩裕, 周悦, 于华 英, 王天舒. 2016. 近年来中国雾研究进展. 气象科技进展, 6: 619

誉梅娟, 李良福, 李子华, 黄建平. 2001. 西双版纳地区雾的物理过程 研究. 气象科学, 21: 425-432

兴梅娟, 张国正, 严文莲, 李子华. 2008. 一次罕见的平流辐射雾过程 的特征. 中国科学D辑: 地球科学, 38: 776-783

孙玉, 焚曙先, 张健, 张悦, 孟庆紫, 何佳宝, 李一. 2015. 南京2013年 冬季三级分粒径雾水化学特征. 中国环境科学, 35: 1019-1031

唐孝炎, 张远航, 邵敏. 2006. 大气环境化学. 北京: 高等教育出版社. 368-370

王雷, 金宜英, 李润东, 聂永丰. 2010. 生活垃圾焚烧飞灰的污染特性. 环境科学与技术, 33: 21-26

王体健, 高太长, 张宏昇, 葛茂发, 雷恒池, 张培昌, 张鹏, 陆春松, 刘 超, 张华. 2019. 新中国成立70年来的中国大气科学研究: 大气物 理与大气环境篇. 中国科学: 地球科学, 49: 1833-1874

王元, 牛生杰, 吕晶晶, 王静, 胡春阳. 2019. 南京冬季一次强浓雾及 超细粒子累积过程分析. 中国环境科学, 39: 459-468

吴兑, 邓雪娇, 毛节泰, 毛伟康, 叶燕翔, 毕雪岩, 唐浩华, 万齐林. 2007. 南岭大瑶山高速公路浓雾的宏微观结构与能见度研究. 气 象学报, 65: 406-415

薛永刚, 龚平, 王小萍, 姚檀栋. 2013. 持久性有机污染物在森林生态
系统中的环境行为研究. 地理科学进展, 32: 278-287

张鸿伟, 禁曙先, 胡春阳, 朱丹丹, 康博识. 2019. 庐山三级分档雾水 化学特征的对比分析. 中国环境科学, 39: 4589-4598

张晶, 宋清海, 张一平, 邓云, 武传胜. 2018. 西双版纳热带雨林和哀 牢山亚热带常绿阔叶林雾特征研究. 生态学报, 38: 8758-8765

张舒婷, 牛生杰, 赵丽娟. 2013. 一次南海海雾微物理结构个例分析. 大气科学, 37: 552-562

周淑贞, 束炣. 1994. 城市气候学. 北京: 气象出版社. 602

朱涁, 李子华, 黄建平, 杨军, 黄玉生, 黄玉仁. 2000. 西双版纳城、郊 雾水化学组成分析. 环境科学学报, 20: 316-321

Barker E H. 1977. A maritime boundary-layer model for the prediction of fog. Bound-Layer Meteorol, 11: 267-294

Chen J Y, Liu Y G, Zhang M, Peng Y R. 2018. Height dependency of aerosol-cloud interaction regimes. J Geophys Res Atmos, 123: 491506

Chen J Y, Liu Y G, Zhang M H, Peng Y R. 2016. New understanding and quantification of the regime dependence of aerosol-cloud interaction for studying aerosol indirect effects. Geophys Res Lett, 43: $1780-1787$

Collett Jr. J, Iovinelli R, Demoz B. 1995. A three-stage cloud impactor for size-resolved measurement of cloud drop chemistry. Atmos Environ, 29: 1145-1154

Collett Jr. J L, Hoag K J, Sherman D E, Bator A, Richards L W. 1999. Spatial and temporal variations in San Joaquin Valley fog chemistry. Atmos Environ, 33: 129-140

Degefie D T, El-Madany T S, Held M, Hejkal J, Hammer E, Dupont J C, Haeffelin M, Fleischer E B N, Klemm O. 2015. Fog chemical composition and its feedback to fog water fluxes, water vapor fluxes, and microphysical evolution of two events near Paris. Atmos Res, 164-165: 328-338

Dusek U, Frank G P, Hildebrandt L, Curtius J, Schneider J, Walter S, Chand D, Drewnick F, Hings S, Jung D, Borrmann S, Andreae M O. 2006. Size matters more than chemistry for cloud-nucleating ability of aerosol particles. Science, 312: 1375-1378

Fuzzi S, Facchini M C, Orsi G, Lind J A, Wobrock W, Kessel M, Maser R, Jaeschke W, Enderle K H, Arends B G, Berner A, Solly I, Kruisz C, Reischl G, Pahl S, Kaminski U, Winkler P, Ogren J A, Noone K J, Hallberg A, Fierlinger-Oberlinninger H, Puxbaum H, Marzorati A, Hansson H C, Wiedensohler A, Svenningsson I B, Martinsson B G, Schell D J, Georgii H W. 1992. The Po valley fog experiment 1989. Tellus B-Chem Phys Meteor, 44: 448-468

Gao S, Lu C, Liu Y, Mei F, Wang J, Zhu L, Yan S. 2020. Contrasting scale dependence of entrainment-mixing mechanisms in stratocumulus clouds. Geophys Res Lett, 47: e86970

Gultepe I, Pearson G, Milbrandt J A, Hansen B, Platnick S, Taylor P, Gordon M, Oakley J P, Cober S G. 2009. The fog remote sensing 
and modeling field project. Bull Amer Meteor Soc, 90: 341-359

Gultepe I, Tardif R, Michaelides S C, Cermak J, Bott A, Bendix J, Müller M D, Pagowski M, Hansen B, Ellrod G, Jacobs W, Toth G, Cober S G. 2007. Fog research: A review of past achievements and future perspectives. Pure Appl Geophys, 164: 1121-1159

Haeffelin M, Bergot T, Elias T, Tardif R, Carrer D, Chazette P, Colomb M, Drobinski P, Dupont E, Dupont J C, Gomes L, Musson-Genon L, Pietras C, Plana-Fattori A, Protat A, Rangognio J, Raut J C, Rémy S, Richard D, Sciare J, Zhang X. 2010. PARISFOG: Shedding new light on fog physical processes. Bull Amer Meteor Soc, 91: $767-783$

Jakob A, Stucki S, Struis R P W J. 1996. Complete heavy metal removal from fly ash by heat treatment: Influence of chlorides on evaporation rates. Environ Sci Technol, 30: 3275-3283

Korolev A, Isaac G A. 2006. Relative humidity in liquid, mixed-phase, and ice clouds. J Atmos Sci, 63: 2865-2880

Lamb D, Verlinde J. 2011. Physics and Chemistry of Clouds. New York: Cambridge University Press. 461-465

Lathem T L, Nenes A. 2011. Water vapor depletion in the DMT continuous-flow $\mathrm{CCN}$ chamber: Effects on supersaturation and droplet growth. Aerosol Sci Tech, 45: 604-615

Li Z H, Liu D Y, Yan W L, Wang H B, Zhu C Y, Zhu Y Y, Zu F. 2019. Dense fog burst reinforcement over Eastern China: A review. Atmos Res, 230: 104639

Liu W J, Liu W Y, Li P J, Duan W P, Li H M. 2010. Dry season water uptake by two dominant canopy tree species in a tropical seasonal rainforest of Xishuangbanna, SW China. Agric For Meteor, 150: 380-388

Lu C, Liu Y, Yum S S, Chen J, Zhu L, Gao S, Yin Y, Jia X, Wang Y. 2020. Reconciling contrasting relationships between relative dispersion and volume-mean radius of cloud droplet size distributions. J Geophys Res Atmos, 125: e31868

Lu C S, Niu S J, Liu Y G, Vogelmann A M. 2013. Empirical relationship between entrainment rate and microphysics in cumulus clouds. Geophys Res Lett, 40: 2333-2338

Lu C S, Niu S J, Tang L L, Lv J J, Zhao L J, Zhu B. 2010. Chemical composition of fog water in Nanjing area of China and its related fog microphysics. Atmos Res, 97: 47-69

Mazoyer M, Burnet F, Denjean C, Roberts G C, Haeffelin M, Dupont J C, Elias T. 2019. Experimental study of the aerosol impact on fog microphysics. Atmos Chem Phys, 19: 4323-4344

Mazzoleni L R, Ehrmann B M, Shen X, Marshall A G, Collett Jeffrey L. J. 2010. Water-soluble atmospheric organic matter in fog: Exact masses and chemical formula identification by ultrahigh-resolution fourier transform ion cyclotron resonance mass spectrometry. Environ Sci Technol, 44: 3690-3697
Nieberding F, Breuer B, Braeckevelt E, Klemm O, Song Q H, Zhang Y P. 2018. Fog water chemical composition on Ailaoshan Mountain, Yunnan Province, SW China. Aerosol Air Qual Res, 18: 37-48

Niu S J, Liu D Y, Zhao L J, Lu C S, Lv J J, Yang J. 2012. Summary of a 4-year fog field study in northern Nanjing, part 2: Fog microphysics. Pure Appl Geophys, 169: 1137-1155

Niu S J, Lu C S, Yu H Y, Zhao L J, Lv J J. 2010. Fog research in China: An overview. Adv Atmos Sci, 27: 639-662

Ogren J A, Noone K J, Hallberg A, Heintzenberg J, Schell D, Berner A, Solly I, Kruisz C, Reischl G, Arends B G, Wobrock W. 1992. Measurements of the size dependence of the concentration of nonvolatile material in fog droplets. Tellus B-Chem Phys Meteor, 44: $570-580$

Petters M D, Kreidenweis S M. 2007. A single parameter representation of hygroscopic growth and cloud condensation nucleus activity. Atmos Chem Phys, 7: 1961-1971

Pilié R J, Mack E J, Rogers C W, Katz U, Kocmond W C. 1979. The formation of marine fog and the development of fog-stratus systems along the California Coast. J Appl Meteor, 18: 1275-1286

Pöschl U, Martin S T, Sinha B, Chen Q, Gunthe S S, Huffman J A, Borrmann S, Farmer D K, Garland R M, Helas G, Jimenez J L, King S M, Manzi A, Mikhailov E, Pauliquevis T, Petters M D, Prenni A J, Roldin P, Rose D, Schneider J, Su H, Zorn S R, Artaxo P, Andreae M O. 2010. Rainforest aerosols as biogenic nuclei of clouds and precipitation in the Amazon. Science, 329: 1513-1516

Raja S, Raghunathan R, Yu X Y, Lee T, Chen J, Kommalapati R R, Murugesan K, Shen X H, Yuan Q Z, Valsaraj K T, Collett J L. 2008. Fog chemistry in the Texas-Louisiana Gulf Coast corridor. Atmos Environ, 42: 2048-2061

Rodhe B. 1962. The effect of turbulence on fog formation. Tellus, 14: 49-86

Román-Cascón C, Yagüe C, Steeneveld G J, Sastre M, Arrillaga J A, Maqueda G. 2016. Estimating fog-top height through near-surface micrometeorological measurements. Atmos Res, 170: 76-86

Seinfeld J H, Pandis S N. 2016. Atmospheric Chemistry and Physics: From Air Pollution to Climate Change. Hoboken: John Wiley \& Sons. 712-715

Shen C, Zhao C, Ma N, Tao J, Zhao G, Yu Y, Kuang Y. 2018. Method to estimate water vapor supersaturation in the ambient activation process using aerosol and droplet measurement data. J Geophys Res Atmos, 123: 10606-10619

Song Q H, Deng Y, Zhang Y P, Deng X B, Lin Y X, Zhou L G, Fei X H, Sha L Q, Liu Y T, Zhou W J, Gao J B. 2017. Comparison of infrared canopy temperature in a rubber plantation and tropical rain forest. Int J Biometeorol, 61: 1885-1892

Spiegel J K, Zieger P, Bukowiecki N, Hammer E, Weingartner E, 
Eugster W. 2012. Evaluating the capabilities and uncertainties of droplet measurements for the fog droplet spectrometer (FM-100). Atmos Meas Tech, 5: 2237-2260

Twomey S. 1974. Pollution and the planetary albedo. Atmos Environ, 8: $1251-1256$

Twomey S. 1977. The influence of pollution on the shortwave Albedo of clouds. J Atmos Sci, 34: 1149-1152

Wallace J M, Hobbs P V. 2006. Atmospheric Science: An Introductory Survey. 2nd ed. Cambridge: Elsevier Academic Press. 221-224

Wang T S, Niu S J, Lv J J, Zhou Y, Wang Y. 2019. Observation and simulation studies of three types of wire icing. Atmosphere, 10: 234
Wang Y, Niu S J, Lu C S, Fan S X, Lv J J, Xu X Q, Jin Y C, Sun W. 2021. A new CCN activation parameterization and its potential influences on aerosol indirect effects. Atmos Res, 253: 105491

Wang Y, Niu S J, Lu C S, Liu Y G, Chen J Y, Yang W X. 2019b. An observational study on cloud spectral width in North China. Atmosphere, 10: 109

Wang Y, Niu S J, Lv J J, Lu C S, Xu X Q, Wang Y Y, Ding J, Zhang H W, Wang T S, Kang B S. 2019a. A new method for distinguishing unactivated particles in cloud condensation nuclei measurements: Implications for aerosol indirect effect evaluation. Geophys Res Lett, 46: 14185-14194

(责任编委: 张宏昇) 